\title{
Hepatotoxicity Secondary to Chemotherapy
}

\author{
Alla Grigorian and Christopher B. O’Brien \\ Divisions of Liver and GI Transplantation, University of Miami School of Medicine, Miami, FL, USA
}

\begin{abstract}
The difficult problem faced by multiple generation of practicing physicians is determining the cause of abnormal liver function tests in cancer patients on chemotherapy. Hepatotoxicity from chemotherapy occurs frequently from an unpredictable or idiosyncratic reaction. Despite remarkable advances in our understanding of the mechanisms of action, pharmacodynamics, and interrelationships between the liver and chemotherapy, the underlying etiology of hepatic toxicity for various agents remains unexplained. Here, we present a concise review of the broad differential diagnosis for abnormal liver function tests (LFTs) in oncology patients.

(c) 2014 The Second Affiliated Hospital of Chongqing Medical University. Published by XIA \& HE Publishing Ltd. All rights reserved.
\end{abstract}

\section{Introduction}

In the complex world of cancer therapy, the administration of medications intentionally designed to be cytotoxic inevitably causes negative consequences. The liver is the primary site of metabolism for many of these drugs, and this liver-drug interaction must be accounted for while dosing chemotherapy. Preexisting liver disease can impair the process of recovery after injury, ${ }^{1}$ and in preparation for chemotherapy, oncologists need to assess both liver function and potential liver involvement by the cancer.

\section{Guidelines for monitoring potential hepatotoxicity}

\section{National Cancer Institute (NCI) common toxicity criteria for adverse events}

Close liver function monitoring is advised for patients starting new chemotherapy regimen. It remains controversial how often liver testing should be performed and what constitutes liver dysfunction. The NCI in the "Common Toxicity Criteria for Adverse Events" has classified elevations of serum

Keywords: Hepatotoxicity; Drugs; Cancer; Chemotherapy; Liver.

Abbreviations: 5-FU, 5-fluorouracil; 5FUDR, fluorodeoxyuridine; 6-MP, 6 mercaptopurine; 6-TG, 6-thioguanine; ALP, alkaline phosphatase; ALT, alanine aminotransferase; AST, aspartate aminotransferase; AZA, azathioprine; DILI, drug induced liver injury; GGT, $\gamma$-glutamyltransferase; HCC, hepatocellular carcinoma; IBD, inflammatory bowel disease; MTX, methotrexate; NCI, National Cancer Institute; ULN, upper limits of normal; VOD, veno-occlusive disease.

Received: 4 March 2014; Revised: 6 May 2014; Accepted: 22 May 2014 DOI of original article: 10.14218/JCTH.2014.00011.

Correspondence to: Alla Grigorian, Divisions of Liver and GI Transplantation, University of Miami School of Medicine, 1500 NW. $12^{\text {th }}$ Ave, Suite 1101 , Miami, FL 33136, USA. Tel: +1-305-243-6956, Fax: +1-305-243-6681, Email: a.grigorian@ med.miami.edu enzyme activities (alanine aminotransferase" (ALT), aspartate aminotransferase (AST), alkaline phosphatase (ALP), and $\gamma$-glutamyltransferase (GGT)) into mild (grade 1 ) if $>$ ULN (upper limits of normal) to $2.5 \times \mathrm{ULN}$; moderate (grade 2 ) if $>2.5$ to $5 \times$ ULN; severe (grade 3 ) if $>5$ to $20 \times$ ULN; and lifethreatening (grade 4) if $>20 \times U L N$; and with no definition for fatal (grade 5). Similarly, they graded serum total bilirubin concentration as mild if $>$ ULN to $1.5 \times$ ULN, moderate if $>1.5$ to $3 \times U L N$, severe if $>3$ to $8 \times U L N$, and life-threatening if $>8 \times$ ULN. Although this grading system is commonly used, this practice has been questioned since the elevation of enzymes by itself does not always reflect dysfunction of the liver and can therefore be misleading.

\section{National Institute of Health Drug Induced Liver Injury (DILI) network}

The National Institute of Health funded DILI network experts proposed to use clinical measures instead of laboratory values and defined liver injury as follows: level 1 (mild) if patient has isolated elevation of ALT and or ALP, level 2 (moderate) in presence of elevated bilirubin and coagulopathy, level 3 (serious) if it results in hospitalization or disability to do usual work; level 4 as acute liver failure, in which another organ that is dependent on liver function shows dysfunction (brain, encephalopathy; kidney, renal insufficiency; etc.); and level 5 as death or liver transplantation. ${ }^{2}$ They also proposed a scale of increasing likelihood, ranging from unlikely to definite, of a suspected case of liver injury to be related to the imputed drug.

\section{Dose modification guidelines}

\section{Liver metabolized agents}

There is agreement on the need for dose reduction for agents that are dependent upon liver metabolism for clearance from the circulation. The major chemotherapeutic agents in this group include methotrexate, sorafenib, dactinomycin, ifosfamide, gemcitabine, etoposide, irinotecan, procarbazine, 6mercaptopurine, cytarabine, crizotinib, and cyclophosphamide.

\section{Chemotherapy to be used with caution}

Certain chemotherapeutic agents must be used with extreme caution in patient with preexisting liver disease. These include the anthracyclines, taxanes, vinca alkaloids, temsirolimus, imatinib, axitinib, lapatinib, erlotinib, nilotinib, pazopanib, ponatinib, and ruxolitinib. 
Grigorian A. et al.: Hepatotoxicity secondary to chemotherapy

\section{Overall guidelines}

The clinical presentations of hepatotoxicity vary from asymptomatic, increase of liver chemistries, overt cholestatic hepatitis, progression to fibrosis and cirrhosis, malignant transformation, veno-occlusive disease/sinusoidal obstruction, and fulminant hepatic failure. Table 1 lists proposed mechanisms of hepatic injury for commonly used chemotherapeutics; it is based mainly on evidence derived from caseseries and case reports.

Table 1. Chemotherapy drugs and liver side effects

\begin{tabular}{|c|c|c|c|c|c|c|}
\hline Drug & Hepatitis & Cholestasis & $\begin{array}{l}\text { Biliary } \\
\text { Stricture }\end{array}$ & Steatosis & $\begin{array}{l}\text { Nodular Hyperplasia } \\
\text { Fibrosis }\end{array}$ & $\begin{array}{l}\text { Veno-Occlusive } \\
\text { Disease }\end{array}$ \\
\hline Actinomycin & Rare & & & & & Rare \\
\hline \multicolumn{7}{|l|}{ Arsenic } \\
\hline Asparaginase & Common & & & Common & & \\
\hline Azathioprine & & Rare & & & & Rare \\
\hline Bleomycin & Rare & & & & & \\
\hline Bortezomib & Rare & & & & & \\
\hline Busulfan & Rare & Rare & & & & Rare \\
\hline Capecitabine & Rare & & & & & \\
\hline Carmustine & Common & & & & & \\
\hline Chlorambucil & & Rare & & & & \\
\hline Cyclophosphamide & Rare & & & & & Common \\
\hline Cytarabine & & Rare & Common & & & \\
\hline Dacarbazine & & & & & & Rare \\
\hline Docetaxel & & Rare & & & & \\
\hline Doxorubicin & Rare & Rare & & & & Rare \\
\hline Erlotinib & & Common & & & & \\
\hline Etoposide & Rare & Rare & & & & \\
\hline Floxuridine & Common & Common & Common & & & \\
\hline Fluorouracil & Rare & & & Common & & Rare \\
\hline Gefitinib & Rare & & & & & \\
\hline Gemcitabine & Rare & Rare & & & & \\
\hline Hydroxyurea & Rare & & & & & \\
\hline Ifosfamide & Rare & & & & & \\
\hline Imatinib & Common & & & & & \\
\hline Interferon & Common & & & & & \\
\hline Interleukin & & Common & & & & \\
\hline Irinotecan & & & & Rare & & \\
\hline Lomustine & Rare & & & & & \\
\hline Melphalan & Rare & & & & & Rare \\
\hline Mercaptopurine & Rare & Rare & & & & \\
\hline Methotrexate & Common & & & & Common & \\
\hline Mitomycin & Rare & & & & & Rare \\
\hline Oxaliplatin & & & & Rare & Rare & Common \\
\hline Paclitaxel & & Rare & & & & \\
\hline Pazopanib & Common & & & & & \\
\hline Procarbazine & Rare & & & & & \\
\hline Regorafenib & Rare & & & & & \\
\hline Sorafenib & Rare & Rare & & & & \\
\hline Streptozocin & Rare & & & & & \\
\hline Thioguanine & & & & & Rare & Rare \\
\hline Topotecan & & Rare & & & & \\
\hline Vincristine & Rare & & & & & \\
\hline Vinorelbine & & Rare & & & & \\
\hline
\end{tabular}


Since there are no perfect laboratory tests that will predict the likelihood of serious liver injury prior to administration of the drug, clinicians are tasked with detecting the early signs of injury and determining whether the drug should be stopped due to hepatotoxicity or to continue chemotherapy if hepatic adaptation and tolerance development are likely. In most cases of DILI, the only effective treatment is discontinuation of the causal agent and supportive care. In the context of lifethreatening disease, the risk and benefit need to be calculated based on the individual patient and disease course.

\section{Specific chemotherapy}

\section{Anti-metabolites}

\section{6-Mercaptopurine (6-MP)}

The largest series, Present et al. reported long-term results of 6-MP use in 396 patients with inflammatory bowel disease (IBD). There were 11 cases of hepatitis and one case of recurrence of jaundice after reinstitution of the drug. ${ }^{3}$ Severe cholestasis associated with the use of conventional doses of 6-MP has also been reported after liver transplantation. ${ }^{4}$ The most common pattern of described injury is intrahepatic cholestasis. Jaundice resolved with discontinuation of the drug. Cases of fulminant hepatic failure occurred with the doses of medication far exceeding the current recommended dose of $1.5 \mathrm{mg} / \mathrm{kg}$ body weight per day.

\section{Azathioprine (AZA)}

Despite being the parental drug of 6-MP, AZA has been linked to little hepatotoxicity. Nevertheless, caution is advised since cholestatic liver injury appears to be possible after prolonged use. Fulminant liver failure was reported in one patient after eight years of dose AZA therapy at levels higher than the currently recommended dose. ${ }^{5}$ AZA related hepatotoxicity was also reported in liver transplant recipients. ${ }^{6}$

\section{6-Thioguanine (6-TG)}

6-TG was reported to cause hepatic vascular disease ${ }^{7}$ and to present significant risk for nodular hyperplasia and early fibrosis. $^{8}$

\section{Cytarabine}

Despite various degrees of hepatic enzyme abnormalities in 42 out of 116 patients in a study, ${ }^{9}$ the definite association with the drug administration was not confirmed. This finding was echoed in a subsequent study with high dose of the drug. Abnormalities in liver function occurred in 14 (22\%) patients (severe in three), but no treatment modifications were required. ${ }^{10}$ Nevertheless, there are reports of severe druginduced hepatic cholestasis related to cytarabine therapy. ${ }^{11}$

\section{5-Fluorouracil (5-FU)}

5-Fluorouracil is commonly used in combination regimen for neoadjuvant chemotherapy in patients with colorectal liver metastasis prior to surgical resection. In a study of 107 patients assigned to receive 5-FU, no significant hepatic toxicity was observed in a group receiving 5-FU orally and was seen infrequently in those receiving the drug intravenously. ${ }^{12}$
Another study retrospectively evaluated the surgical specimen with focus on liver parenchyma not involved by the resected tumor. ${ }^{13}$ Overall, sinusoidal obstruction was present in 39 patients $(10 \%)$, steatosis in $134(35 \%)$, and steatohepatitis in $16(4 \%)$. A recent study which attempted to stratify patients based on degree of hepatic dysfunction reported no difference in the 5-FU clearance in patients with elevated bilirubin. ${ }^{14}$

\section{Fluorodeoxyuridine (5FUDR)}

In a study comparing regional intra-arterial versus continuous systemic therapy with 5FUDR in patients with colorectal liver metastasis, there was considerable hepatotoxicity, including chemical hepatitis in $79 \%$ of patients and biliary sclerosis is $21 \%$ of patients. The small gain in survival seen with regional therapy was offset by toxicity of intra-arterial FUDR. ${ }^{15}$ In later studies, biliary toxicity called for reduction of the dose and the duration of therapy with more than half of patients requiring treatment termination due to drug toxicity. ${ }^{16}$ It is still a matter of debate whether bile duct injury is related to drug toxicity or ischemia. ${ }^{17}$

\section{Capecitabine}

Capecitabine is a drug that undergoes preferential conversion to 5-fluorouracil within the tumor. A study of 14 patients investigated the pharmacokinetics of the drug in patients with hepatic dysfunction and concluded that mild to moderate hepatic dysfunction had no clinically significant influence. ${ }^{18}$ This was confirmed in a recent study, which examined the impact of hepatic dysfunction on the safety and pharmacology of gemcitabine/capecitabine in patients with advanced pancreatico-biliary cancer. Eight patients with hepatic dysfunction and bilirubin elevation (ranging $1.2-6.6 \mathrm{mg} / \mathrm{dL}$ ) were included. Combination therapy was well tolerated, and hepatic dysfunction was not associated with drug-related toxicity. ${ }^{19}$

\section{Gemcitabine}

In a Phase I trial in patients with hepatic dysfunction, 25 patients were divided in two groups: elevated AST and mildly and moderately elevated bilirubin. AST levels ranged from 37 to $530 \mathrm{U} / \mathrm{L}$, and bilirubin from normal up to $5.7 \mathrm{mg} / \mathrm{dL}$. The most common dose limiting side effect was transient elevation in baseline bilirubin in seven patients from the second group. The authors of this trial recommended decreasing the initial dose of medication in patients with elevated baseline bilirubin. ${ }^{20}$ This conclusion was not confirmed in a retrospective review of treatment with gemcitabine in seven patients with hepatic dysfunction and bilirubin elevation (total bilirubin $>4.5 \mathrm{mg} / \mathrm{dL}$ ). Full dose of gemcitabine in this study did not result in further deterioration of liver function. ${ }^{21}$

Methotrexate (MTX)

With MTX therapy, the incidence of abnormalities in hepatic function tests for ALT and AST were reported to be $14 \%$ and $8 \%$, respectively. ${ }^{22}$ This finding was replicated recently with a recent meta-analysis where the pooled frequency of liver enzyme abnormalities was $10.2 \% .^{23}$ In a historic report, of the use of "antifolics" and "antipurins" in children with acute leukemia was associated with fibrosis in $80 \%$ of children based on histology and clinical evidence of liver disease in 
almost all cases. ${ }^{24}$ Cases of hepatocellular carcinoma (HCC) in long-term survivors of childhood leukemia have been reported. ${ }^{25}$ In addition, methotrexate induced cirrhosis has resulted in liver transplantation in a number of patients. ${ }^{26}$

Despite the concerns spanning half of a century for the potential risk for hepatic cirrhosis with the use of methotrexate in nonmalignant diseases such as psoriasis, ${ }^{27}$ later studies in patients with rheumatoid arthritis ${ }^{28}$ alleviated some of the fears. However, "word of caution" still requires very close patient monitoring, in particular in those with concurrent obesity and diabetes. ${ }^{29}$

\section{Alkylating agents}

Busulfan

Oral Busulfan has been implicated in severe cases of hepatic veno-occlusive disease. ${ }^{30}$ In a study with intravenous Busulfan in 55 pediatric patients, mild to moderate transient elevation in liver enzymes and bilirubin was described. Although veno-occlusive disease (VOD) occurred in up to 15 $\%$ of patients, reported cases were mild and resolved in ten days after diagnosis. ${ }^{31}$

\section{Cyclophosphamide}

Cyclophosphamide is used in the most liver toxic myeloablative regimen, and when combined with total body irradiation, has been reported to result in VOD in $38 \%$ of the patients. ${ }^{32}$ The hepatotoxicity appeared to be greatly potentiated by radiation. Cyclophosphamide was demonstrated in seven patients with liver dysfunction to have a significantly longer half-life. ${ }^{33}$

\section{Chlorambucil}

There are few available reports regarding liver toxicity of chlorambucil, but the largest one found jaundice in $7.2 \%$ patients undergoing treatment for lymphoma and leukemia. ${ }^{34}$

\section{Ifosfamide}

Ifosfamide is not commonly associated with hepatotoxicity. In one phase II trial of 19 patients with HCC in the background of viral hepatitis and cirrhosis (bilirubin $<3.0 \mathrm{mg} / \mathrm{dL}$ ), direct intra-arterial delivery of the drug to the tumor was reported to worsen liver function in two patients. ${ }^{35}$

Melphalan

Hepatotoxicity with melphalan has been reported infrequently. Its use has been associated with transient elevation of transaminases ${ }^{36}$ and VOD. ${ }^{37}$ In the past decade, isolated hepatic perfusion of the liver for metastatic disease was advocated and more severe hepatotoxicity was observed in a study where 16 of 71 patients exhibited level 3-4 hepatic toxicity after one week of treatment. ${ }^{38}$

\section{Antitumor antibiotics}

Actinomycin

Hypersensitivity reaction to actinomycin has been reported with acute presentation and a sharp drop in platelet count, fever, and a rise in transaminases. ${ }^{39}$ In a study analyzing the toxicity data for 511 children, $64(12.5 \%)$ had at least one episode of hepatotoxicity and 41 satisfied the criteria for VOD, with $94 \%$ overall survival in this group. ${ }^{40}$

\section{Bleomycin}

Studies with bleomycin described mild transient abnormalities in liver enzymes with a return to baseline upon cessation of drug treatment and no specific pathological liver abnormalities. ${ }^{41}$

\section{Doxorubicin/Adriamycin}

Adriamycin dosing in hepatic dysfunction received attention because of reported excessive life -threatening toxicity, as demonstrated with liver test abnormalities, in eight patients. ${ }^{42}$ The investigators reduced the dose of the drug in the subsequent nine patients to $50 \%$ of the dose in patients with bilirubin of $1.2-3.0 \mathrm{mg}$ and $75 \%$ of the dose if bilirubin measured $>3.0 \mathrm{mg}$. This approach succeeded and was adopted by clinical community. In contrast, liver cirrhosis did not seem to affect drug metabolism in a study of seven patients, three of which had biopsy proven cirrhosis. ${ }^{43}$

Mitomycin

Mitomycin can cause transient jaundice ${ }^{44}$ and has been implicated in VOD. ${ }^{45}$

\section{Dacarbazine}

Dacarbazine was associated in one report with hepatic necrosis with thrombotic occlusion of the small vessels in two of sixty-eight patients (3\%). ${ }^{46}$

\section{Nitrosoureas}

\section{Carmustine}

With carmustine, liver enzymes were elevated, unexplained by the primary disease, in $26 \%$ of patients. ${ }^{47}$

\section{Lomustin}

In a trial of lomustin with 142 patients with advanced solid tumors, reports of transient hepatic toxicity was reported much less frequently and consisted of elevation of ALP, ALT, and AST in two patients. ${ }^{48}$

\section{Streptozotocin}

In a study of streptozotocin with 88 patients with advanced malignancy, hepatotoxicity, manifesting as elevation of transaminases, was demonstrated in $13(15 \%)$. The enzymes rapidly returned to normal after discontinuation of therapy, and no signs of hepatocellular necrosis were found on histological examination. ${ }^{49}$

\section{Taxanes}

Paclitaxel

In a study of paclitaxel with 81 patients with solid tumors and abnormal hepatic function, three groups were evaluated 
based on the level of bilirubin and AST. ${ }^{50}$ The elevation of bilirubin above $1.5 \mathrm{mg} / \mathrm{dL}$ with any level of AST predicted drug-related toxicity with 24 hour infusion, and dose reduction was recommended. The study with 3-hour infusion confirmed a higher incidence of toxicities in severe liver dysfunction groups (bilirubin $>2.0 \mathrm{mg} / \mathrm{dL}$ ). The study included two patients with liver cirrhosis. ${ }^{51}$

\section{Docetaxel}

In a study of 42 patients with moderate hepatic impairment, the docetaxel dose had to be reduced due to increased incidence of drug-related toxicities following treatment. ${ }^{52}$ However, in a study of patients with hepatic dysfunction secondary to metastatic breast cancer, almost half of group allowed initial dose escalation due to improved liver function as an indicator of the tumor response to treatment. ${ }^{53}$

\section{Vinca alkaloids}

\section{Vincristine}

Transient elevation of transaminases following vincristine therapy has been described, and it seems to be greatly potentiated by radiation therapy. ${ }^{54}$ Since neurotoxicity, the most feared side effect, has been shown to be dose dependent, much attention has been paid its reduced elimination in liver dysfunction. A study of 39 patients suggested that elevation in ALP is the most sensitive parameter in predicting reduced clearance. ${ }^{55}$

\section{Vinorelbine}

In a study of oral and intravenous vinorelbine, the drug exposure was not affected by mild to moderate hepatic dysfunction (bilirubin $<3.0 \mathrm{mg} / \mathrm{dL}$ ). ${ }^{56}$ In contrast, another study assessed patients with impaired liver function due to metastatic disease and established that increased systemic exposure with high risk of toxicity occurred in the group with hyperbilirubinemia $(>1.5 \mathrm{mg} / \mathrm{dL}) .{ }^{57}$

\section{Topoisomerase inhibitors}

\section{Topotecan}

Rapid transient elevation of serum bilirubin without significant elevation in transaminases was noticed in patients in a phase I trial of topotecan. ${ }^{58}$ Due to its known hepatic route of elimination, a study of 21 patients (mean bilirubin $4.3 \mathrm{mg} / \mathrm{dL}$ ) was conducted to establish dosing guidelines in patients with impaired liver function. ${ }^{59}$ No increase in toxicity was observed, and worsening of hepatic function in several patients was attributed to disease progression. This study concluded that no dose adjustment is necessary with impaired liver function.

\section{Irinotecan}

Dose reduction was suggested for irinotecan in patients with elevated baseline bilirubin and transaminases, as one study showed an increased incidence of neutropenia and doselimiting elevation in transaminases in a group with hepatic dysfunction (AST 134-394 U/l, bilirubin $0.7-5.5 \mathrm{mg} / \mathrm{dl}$ ). ${ }^{60}$ Irinotecan is used in a preoperative chemotherapy regimen prior to resection of hepatic colorectal metastasis. It has been linked to the development of steatohepatitis, which contributed to increased postoperative mortality in a large cohort of patients. ${ }^{61}$

\section{Etoposide}

Topoisomerase II inhibitor Etoposide had been described to cause severe hepatocellular injury. ${ }^{62}$ Studies in patients with impaired hepatic function (bilirubin up to $23 \mathrm{mg} / \mathrm{dL}$ ) showed no change in etoposide clearance. ${ }^{63}$

\section{Platinum agents}

A pilot study of 11 patients with hepatic dysfunction (bilirubin $>1.5$ times ULN) due to breast cancer metastatic to the liver reported normalization of the liver function tests, a marker of tumor responsiveness, to administered therapy in ten patients. ${ }^{64}$

Oxaliplatin

Oxaliplatin associated hepatic vascular injury has been described in multiple studies. A large series that evaluated 153 liver resection specimens found sinusoidal congestion of various degrees in 44 patients, perisinusoidal fibrosis and fibrotic venular occlusion in 21 patients, nodular regenerative hyperplasia in seven patients, and hepatic steatosis in 75 patients. ${ }^{65}$ Another study assessed the risk of preoperative chemotherapy in patients undergoing liver resection for colorectal cancer metastasis. Out of 166 patients treated with oxaliplatin, $11 \%$ developed sinusoidal dilatation. No increase in postoperative morbidity was found, suggesting this histopathology finding does not independently increase the operative risk. ${ }^{66}$

A phase I study administered reduced schedule dose of oxaliplatin to 47 patients with impaired liver function, including 16 patient with severe dysfunction (bilirubin $>3.0 \mathrm{mg} / \mathrm{dL}$ ). No dose limiting toxicities were observed in any cohort of the patients with escalation of the dose to the conventionally used level. ${ }^{67}$

\section{Tyrosine kinase inhibitors}

The discovery of targeted inhibition of tyrosine kinase (a family of proteins frequently dysregulated in various cancers) marked a breakthrough in the fight against cancer. The unique properties of these medications helped to avoid conventional toxicities, while hepatotoxicity emerged as a dose-limiting event. The risk of grade 3 hepatic adverse events with TKIs has been reported in the range of $1 \%$ to $12 \% .{ }^{68}$

\section{Erlotinib}

Transient grade 1-2 hyperbilirubinemia was reported in a phase I clinical trial of erlotinib. ${ }^{69}$ However, in a recent study, grade 3-4 bilirubin elevation was described in $47 \%$ of patients with preexisting moderate hepatic dysfunction. ${ }^{70}$

\section{Gefitinib}

Use of Gefitinib in treatment of advanced metastatic nonsmall cell lung cancers was linked with grade 3 elevation of ALT $2 \%$ of 147 patients receiving medication. ${ }^{71}$ 
Imatinib

In a study of 89 patient with solid cancers and liver dysfunction, up to $58 \%$ of patients with moderate to severe $\mathrm{HD}$, defined as bilirubin $>1.5 \mathrm{ULN}$, had to be withdrawn from the study prematurely due to progressive elevation of LFTs. ${ }^{72}$ Another study of 551 patients with chronic myeloid leukemia treated with Imatinib reported elevation of serum aminotransferases in $43 \%$ of patients, with grade $3-4$ in $5 \% .^{73}$

Pazopanib

Due to concern of hepatotoxicity, a phase I study attempted to define the appropriate dose of Pazopanib in patients with solid tumors and lymphoma and hepatic dysfunction. It was concluded that no dose reduction was necessary in mild cases and reduced dose can be used in patients with moderate dysfunction, defined as bilirubin elevation 1.5-3X ULN. ${ }^{74}$

Sorafenib

In a phase I study of sorafenib in patients with hepatic dysfunction, dose limiting elevation of bilirubin occurred in 10 out of 72 patients, leading to recommendation to lowering the dose to half in patients with bilirubin $>1.5 \times$ ULN and not reaching conclusive safe dose guidelines in patients with bilirubin $>3 \times$ ULN. $^{75}$

\section{Immunotherapy}

Interferon

In patients receiving high-dose Interferon therapy for melanoma, $63 \%$ had hepatic toxicities (all grades). If AST or ALT levels increased $>5$ times normal, this was considered doselimiting toxicity with recommended dose modifications. ${ }^{76}$

Interleukin-2

With interleukin-2 therapy, profound reversible intrahepatic cholestasis was reported in 261 retrospectively and 10 prospectively evaluated patients with cancer, with normalization, on average, in 5.6 days. ${ }^{77}$

\section{Miscellaneous agents}

Arsenic trioxide

In a study examining of the use of arsenic trioxide for newly diagnose promyelocytic leukemia, severe hepatotoxicity resulted in the death of two out of 11 treatment naïve patients. $^{78}$

\section{Asparaginase}

Liver enzyme abnormalities with asparaginase were reported in 33 out of 35 patients in an early study, where liver biopsies found reversible fatty metamorphosis in two patients. ${ }^{79}$

\section{Bortezomib}

Bortezomib was studied in 61 patients with advanced malignancies and varying degrees of hepatic dysfunction. ${ }^{80}$ Since liver failure was reported in one patient, dose adjustment was recommended in patients with moderate to severe hepatic impairment defined as bilirubin $>1.5$ ULN.

Hydroxyurea

Hepatotoxicity appears to be uncommon with hydroxyurea, but there is case report of a self-limiting hepatitis ${ }^{81}$ that recurred upon drug reintroduction.

\section{Procarbazine}

Liver toxicity is not commonly reported with procarbazine, although it has been implicated in the development of hepatic granulomas. $^{82}$

\section{Conclusions}

Collateral damage to the liver in cancer therapy is not uncommon. Hepatotoxicity from chemotherapy occurs frequently in an unpredictable or idiosyncratic fashion, , and preexisting liver disease increases this risk. The pattern of presentation can vary from that of an inflammatory hepatitis, cholestasis, steatosis, and finally a vascular presentation as hepatic VOD. The severity ranges from asymptomatic liver function test elevation, acute liver failure, or a progressive fibrosis culminating in end stage liver disease. Various groups have produced liver toxicity classifications that lay out dose modification guidelines for various chemotherapeutic agents. Nevertheless, with knowledge and caution, many potential side effects and serious damage to the recipient can be avoided.

\section{Conflict of interest}

None

\section{Author contributions}

Writing this article (AG, $C B O)$.

\section{References}

[1] Senior JR. Unintended hepatic adverse events associated with cancer chemotherapy. Toxicol Pathol 2010;38:142-147. doi: 10.1177/0192623309351719.

[2] Fontana RJ, Watkins PB, Bonkovsky HL, Chalasani N, Davern T, Serrano J, et al. Drug-induced liver injury network (DILIN) prospective study: Rationale, design, and conduct. Drug Safety 2009;32:55-68. doi: 10.2165/00002018-200932010-00005.

[3] Present DH, Meltzer SJ, Krumholtz MP, Wolke A, Korelitz BI. 6Mercaptopurine in the management of inflammatory bowel disease: shortand long-term toxicity. Ann Intern Med 1989;111:641-649. doi: 10.7326/ 0003-4819-111-8-641.

[4] Kontorinis N, Agarwala K, Gondolesia G, Fiel MI, O'Rourke M, Schianoa TD. Diagnosis of 6 mercaptopurine hepatotoxicity post liver transplantation utilizing metabolite assays. Am J Transplant 2004;4:1539-1542. doi: 10.1111/j.1600-6143.2004.00543.x.

[5] Barrowman JA, Kutty PK, Ra MU, Huang SN. Sclerosing hepatitis and azathioprine (letter). Dig Dis Sci 1986;31:221-222. doi: 10.1007/BF01300713.

[6] Sterneck M, Wiesner R, Ascher N, Roberts J, Ferrell L, Ludwig J, et al. Azathioprine hepatotoxicity after liver transplantation Hepatology $1991 ; 14$ : 806-810. doi: 10.1002/hep.1840140511.

[7] Satti MB, Weinbren K, Gordon-Smith EC. 6-thioguanine as a cause of toxic veno-occlusive disease of the liver. J Clin Pathol 1982;35:1086-1091. doi: 10.1136/jcp.35.10.1086.

[8] Geller SA, Dubinsky MC, Poordad FF, Vasiliauskas EA, Cohen AH, Abreu MT, et al. Early hepatic nodular hyperplasia and submicroscopic fibrosis associated with 6-thioguanine therapy in inflammatory bowel disease. Am J Surg Pathol 2004;28:1204-1211. doi: 10.1097/01.pas.0000128665.12063.97. 
[9] Ellison RR, Holland JF, Weil M, Jacquillat C, Boiron M, Bernard J, et al. Arabinosyl cytosine: A useful agent in the treatment of acute leukemia in adults. Blood 1968;32:507-523.

[10] Kantarjian HM, Estey EH, Plunkett W, Keating MJ, Walters RS, Iacoboni S, et al. Clinical studies: Phase I II clinical and pharmacologic studies of highdose cytosine arabinoside in refractory leukemia. Am J Med 1986;81:387394. doi: 10.1016/0002-9343(86)90287-1.

[11] Pizzuto J, Avilés A, Ramos E, Cervera J, Aguirre J. Cytosine arabinoside induced liver damage: histopathologic demonstration. Med Pediatr Oncol 1983;11:287-290. doi: 10.1002/mpo.2950110416.

[12] Bateman JR, Pugh RP, Cassidy FR, Marshall GJ, Irwin LE. 5-Fluorouracil given once weekly: Comparison of intravenous and oral administration. Cancer 1971;28:907-913. doi: 10.1002/1097-0142(1971)28:4<907::AIDCNCR2820280414>3.0.CO;2-9.

[13] Wolf PS, Park JO, Bao F, Allen PJ, DeMatteo RP, Fong $Y$, et al. Preoperative chemotherapy and the risk of hepatotoxicity and morbidity after liver resection for metastatic colorectal cancer: a single institution experience. J Am Coll Surg 2013;216:41-49. doi: 10.1016/j.jamcollsurg.2012.08.030.

[14] Fleming GF, Schilsky RL, Schumm LP, Meyerson A, Hong AM, Vogelzang NJ, et al. Phase I and pharmacokinetic study of 24-hour infusion 5-fluorouracil and leucovorin in patients with organ dysfunction. Ann Oncol 2003;14: 1142-1147. doi: 10.1093/annonc/mdg302.

[15] Chang AE, Schneider PD, Sugarbaker PH, Meyerson A, Hong AM, Vogelzang $\mathrm{NJ}$, et al. A prospective randomized trial of regional versus systemic continuous 5-FudR chemotherapy in the treatment of colorectal liver metastases. Ann Surg 1987;206:685-693. doi: 10.1097/00000658198712000-00001.

[16] Hohn DC, Stagg R, Friedman MA, Hannigan JF Jr, Rayner A, Ignoffo RJ, et al. A randomized trial of continuous intravenous versus hepatic intraarterial floxuridine in patients with colorectal cancer metastatic to the liver: The Northern California Oncology Group trial. J Clin Oncol 1989;7:1646-1654.

[17] Ludwig J, Kim CH, Wiesner RH, Krom RA. Floxuridine-induced sclerosing cholangitis: An ischemic cholangiopathy? Hepatology 1989;9:215-218. doi: 10.1002/hep.1840090209.

[18] Doria MI Jr, Shepard KV, Levin B, Riddell RH. Liver pathology following hepatic arterial infusion chemotherapy. Hepatic toxicity with FUDR. Cancer 1986;58:855-861. doi: 10.1002/1097-0142(19860815)58:4<855::AIDCNCR2820580409>3.0.CO;2-6.

[19] Joerger M, Huitema AD, Koeberle D, Rosing H, Beijnen JH, Hitz F. Safety and pharmacology of gemcitabine and capecitabine in patients with advanced pancreatico-biliary cancer and hepatic dysfunction. Cancer Chemother Pharmacol 2014;73:113-124. doi: 10.1007/s00280-013-2327-2.

[20] Venook AP, Egorin MJ, Rosner GL, Hollis D, Mani S, Hawkins M, et al. Phase I and pharmacokinetic trial of gemcitabine in patients with hepatic or renal dysfunction: Cancer and Leukemia Group B 9565. J Clin Oncol 2000;18: 2780-2787.

[21] Teusink AC, Hall PD. Toxicities of gemcitabine in patients with severe hepatic dysfunction. Ann Pharmacother 2010;44:750-754. doi: 10.1345/ aph.1M587.

[22] Berkowitz RS, Goldstein DP, Bernstein MR. Ten year's experience with methotrexate and folinic acid as primary therapy for gestational trophoblastic disease. Gynecol Oncol 1986;23:111-118. doi: 10.1016/00908258(86)90123-X.

[23] Valentino PL, Church PC, Shah PS, Beyene J, Griffiths AM, Feldman BM. Hepatotoxicity Caused by Methotrexate Therapy in Children with Inflammatory Bowel Disease: A Systematic Review and Meta-analysis. Inflamm Bowel Dis 2014;20:47-59. doi: 10.1097/01.MIB.0000436953. 88522.3e.

[24] Hutter RV, Shipkey FH, Tan CT, Murphy ML, Chowdhury M. Hepatic fibrosis in children with acute leukemia: acomplication of therapy. Cancer 1960;13: 288-307. doi: 10.1002/1097-0142(196003/04)13:2<288::AIDCNCR2820130213>3.0.CO;2-L.

[25] Fried M, Kalra J, Ilardi C, Sawitsky A. Hepatocellular carcinoma in a long term survivor of acute lymphocytic leukemia. Cancer 1987;60:2548-2552. doi: 10.1002/1097-0142(19871115)60:10<2548::AID-CNCR2820601033>3.0. $\mathrm{CO} ; 2-\mathrm{H}$.

[26] Gilbert SC, Klintmalm G, Menter A, Silverman A. Methotrexate-induced cirrhosis requiring liver transplantation in three patients with psoriasis. A word of caution in light of the expanding use of this 'steroid sparing'agent. Arch Intern Med 1990;150:889-891. doi: 10.1001/archinte.1990. 00390160129025 .

[27] Zachariae H, Kragballe K, Stogaard H. Methotrexate induced liver cirrhosis. Studies including serial liver biopsies during continued treatment. $\mathrm{Br}$ ] Dermatol 1980;102:407-412. doi: 10.1111/j.1365-2133.1980.tb06553.x.

[28] Rau R, Karger T, Herborn G, Frenzel H. Liver biopsy findings in patients with rheumatoid arthritis undergoing longterm treatment with methotrexate. J Rheumatol 1989;16:489-493.

[29] Kremer JM, Lee RG, Tolman KG. Liver histology in rheumatoid arthritis patients receiving long-term methotrexate therapy. A prospective study with baseline and sequential biopsy samples. Arthritis Rheum 1989;32:121-127. doi: 10.1002/anr.1780320202.

[30] Hassan M. The role of busulfan in bone marrow transplantation. Med Oncol 1999; 16:166-176. doi: 10.1007/BF02906128.

[31] Hoy SM, Lyseng-Williamson KA. Intravenous busulfan: in the conditioning treatment of pediatric patients prior to hematopoietic stem cell transplantation. Paediatr Drugs 2007;9:271-278. doi: 10.2165/00148581-20070904000008.

[32] McDonald GB, Slattery JT, Bouvier ME, Ren S, Batchelder AL, Kalhorn TF, et al. Cyclophosphamide metabolism, liver toxicity, and mortality following hematopoietic stem cell transplantation. Blood 2003;101:2043-2048. doi: 10.1182/blood-2002-06-1860.

[33] Juma FD. Effect of liver failure on the pharmacokinetics of cyclophosphamide.Eur J Clin Pharmacol 1984;26:591-593.

[34] Amromin GD, Deliman RM, Shanbrom E. Liver damage after chemotherapy for leukemia and lymphoma. Gastroenterology 1962;42:401-410.

[35] Malik IA, Khan WA, Haq S, Sabih M. A prospective phase II trial to evaluate the efficacy and toxicity of hepatic arterial infusion of ifosfamide in patients with inoperable localized hepatocellular carcinoma. Am J Clin Oncol 1997;20: 289-292. doi: 10.1097/00000421-199706000-00017.

[36] Pritchard J, McElwain TJ, Graham-Pole J. High-dose melphalan with autologous marrow for treatment of advanced neuroblastoma. $\mathrm{Br}$ J Cancer 1982; 45:86-94. doi: 10.1038/bjc.1982.11.

[37] Graham-Pole J, Lazarus HM, Herzig RH, Gross S, Coccia P, Weiner R, et al. High-dose melphalan therapy for the treatment of children withrefractory neuroblastoma and Ewing's sarcoma. Am J Pediatr Hematol Oncol 1984;6: 17-26.

[38] Rothbarth J, Pigil ME], Vahrmeijer AL. Isolated hepatic perfusion with highdose melphalan for the treatment of colorectal metastasis confined to the liver. Br J Surg 2003;90:1391-1397. doi: 10.1002/bjs.4308.

[39] Davidson A, Pritchard J. Actinomycin D, hepatic toxicity and Wilms' tumour-a mystery explained? Eur J Cancer 1998;34:1145-1147. doi: 10.1016/S09598049(98)80044-0.

[40] Bisogno G, de Kraker J, Weirich A, Masiero L, Ludwig R, Tournade MF, et al. Veno-occlusive disease of the liver in children treated for Wilms tumour. Med Ped Oncol 1997;29:245-251. doi: 10.1002/(SICI)1096-911X(199710)29: 4<245: :AID-MPO2>3.0.CO;2-M.

[41] Yagoda A, Mukherji B, Young C, Etcubanas E, Lamonte C, Smith JR, et al. Bleomycin, an antitumor antibiotic. Clinical experience in 274 patients. Ann Intern Med 1972;77:861-870. doi: 10.7326/0003-4819-77-6-861.

[42] Benjamin RS, Wiernik PH, Bachur NR. Adriamycin chemotherapy-efficacy, safety, and pharmacologic basis of an intermittent single high-dosage schedule. Cancer 1974;33:19-27. doi: 10.1002/1097-0142(197401)33: $1<19$ : :AID-CNCR2820330107>3.0.CO;2-M

[43] Chan KK, Chlebowski RT, Tong M, Chen HS, Gross JF, Bateman JR. Clinical pharmacokinetics of adriamycin in hepatoma patients with cirrhosis. Cancer Res 1980;40:1263-1268.

[44] Robert J, Barbier P, Manaster J, Jacobs E. Hepatotoxicity of cytostatic drugs evaluated by liver function tests and appearance of jaundice. Digestion 1968;1:229-232. doi: 10.1159/000196858.

[45] Lazarus HM, Gottfried MR, Herzig RH, Phillips GL, Weiner RS, Sarna GP, et al. Veno-occlusive disease of the liver after high-dose mitomycin $C$ therapy and autologous bone marrow transplantation. Cancer 1982;49:1789-1795. doi: 10.1002/1097-0142(19820501)49:9<1789::AID-CNCR2820490910>3.0.CO 2-H.

[46] Ceci G, Bella M, Melissari M, Gabrielli M, Bocchi P, Cocconi G. Fatal hepatic vascular toxicity of DTIC. Is it really a rare event? Cancer 1988;61:19881991. doi: 10.1002/1097-0142(19880515)61:10<1988: :AIDCNCR2820611010>3.0.CO;2-5.

[47] DeVita VT, Carbone PP, Owens AH, Gold C L, Krant M J, Edmonson J. Clinical trials with 1,s -bis(2-chloroeth yl) - 1 -nit rosourea, NSC 409962. Cancer Res $1965 ; 25: 1876-1881$.

[48] Hoogstraten B, Gottlieb JA, Caoili E, Tucker WG, Talley RW, Haut A. CCNU [1[2-chloroethyl]-3-cyclohexyl-1-nitrosourea, NSC-79037] in the treatment of cancer. Phase II study. Cancer 1973;32:38-43. doi: 10.1002/10970142(197307)32:1<38::AID-CNCR2820320105>3.0.CO;2-I.

[49] Schein PS, O'Connell MJ, Blom J, Hubbard S, Magrath IT, Bergevin P, et al. Clinical antitumor activity and toxicity of streptozotocin [NSC-85998]. Cancer 1974;34:993-1000. doi: 10.1002/1097-0142(197410)34: 4<993: :AID-CNCR2820340404>3.0.CO;2-T.

[50] Venook AP, Egorin MJ, Rosner GL, Brown TD, Jahan TM, Batist G, Hohl R, et al. Phase I and pharmacokinetic trial of paclitaxel in patients with hepatic dysfunction: Cancer and Leukemia Group B 9264. J Clin Oncol 1998;16: 1811-1819.

[51] Joerger $M$, Huitema AD, Huizing MT, Willemse PH, de Graeff A, Rosing $H$, et al. Safety and pharmacology of paclitaxel in patients with impaired liver function: a population pharmacokinetic-pharmacodynamic study. $\mathrm{Br} \mathrm{J}$ Clin Pharmacol 2007;64:622-633. doi: 10.1111/j.1365-2125.2007.02956.x. 
[52] Burris HA. Optimal use of docetaxel (Taxotere): maximizing its potential. Anticancer Drugs 1996;7:25-28. doi: 10.1097/00001813-19960800200007.

[53] Eckmann K, Michaud LB, Rivera E, Madden TL, Esparza-Guerra L, Kawedia J, et al. Pilot study to assess toxicity and pharmacokinetics of docetaxel in patients with metastatic breast cancer and impaired liver function secondary to hepatic metastases. J Oncol Pharm Pract 2014;20:120-129. doi: $10.1177 / 1078155213480536$.

[54] Hansen MM, Ranek L, Walbom S, Nissen NI. Fatal hepatitis following irradiation and vincristine. Acta Med Scand 1982;212:171-174.

[55] Van den Berg HW, Desai ZR, Wilson R, Kennedy G, Bridges JM, Shanks RG. The pharmacokinetics of vincristine in man: Reduced drug clearance associated with raised serum alkaline phosphatase and dose-limited elimination. Cancer Chemother Pharmacol 1982;8:215-219. doi: 10.1007/ BF00255487.

[56] Kitzen JJ, Puozzo C, de Jonge MJ, Brandely M, Verweij J. Mild to moderate liver dysfunction does not require dose reduction of oral or intravenous vinorelbine: results of a pharmacokinetic study. Eur J Cancer 2010;46:266269. doi: 10.1016/j.ejca.2009.10.031.

[57] Robieux I, Sorio R, Borsatti E, Cannizzaro R, Vitali V, Aita $P$, et al. Pharmacokinetics of vinorelbine in patients with liver metastases. Clin Pharmacol Ther 1996;59:32-40. doi: 10.1016/S0009-9236(96)90021-1.

[58] Rowinsky EK, Kaufmann SH, Baker SD, Miller CB, Sartorius SE, Bowling MK, et al. A phase I and pharmacological study of Topotecan infused over 30 minutes for five days in patients with refractory acute leukemia. Clin Cancer Res 1996;2:1921-1930.

[59] O'Reilly S, Rowinsky E, Slichenmyer W, Donehower RC, Forastiere A, Ettinger $\mathrm{D}$, et al. Phase I and pharmacologic studies of topotecan in patients with impaired hepatic function. J Natl Cancer Inst 1996;88:817-824. doi: 10.1093/jnci/88.12.817.

[60] Venook AP, Enders Klein C, Fleming G, Hollis D, Leichman CG, Hohl R, et al. A phase I and pharmacokinetic study of irinotecan in patients with hepatic or renal dysfunction or with prior pelvic radiation: CALGB 9863. Ann Oncol 2003;14:1783-1790. doi: 10.1093/annonc/mdg493.

[61] Vauthey JN, Pawlik TM, Ribero D, Wu TT, Zorzi D, Hoff PM, et al. Chemotherapy regimen predicts steatohepatitis and an increase in 90-day mortality after surgery for hepatic colorectal metastases. J Clin Oncol 2006; 24:2065-2072. doi: 10.1200/JCO.2005.05.3074.

[62] Tran A, Housset C, Boboc B, Tourani JM, Carnot F, Berthelot P. Etoposide (VP 16213 ) induced hepatitis. Report of three cases following standard-dose treatments. J Hepatol 1991;12:36-39. doi: 10.1016/0168-8278(91)90905-Q.

[63] Arbuck SG, Douglass HO, Crom WR, Goodwin P, Silk Y, Cooper C, et al. Etoposide pharmacokinetics in patients with normal and abnormal organ function. J Clin Oncol 1986;4:1690-1695.

[64] Sharma RA, Decatris MP, Santhanam S, Roy R, Osman AE, Clarke CB, et al. Reversibility of liver failure secondary to metastatic breast cancer by vinorelbine and cisplatin chemotherapy. Cancer Chemother Pharmacol 2003;52:367-370. doi: 10.1007/s00280-003-0679-8.

[65] Rubbia-Brandt L, Audard V, Sartoretti P, Roth AD, Brezault C, Le Charpentier $M$, et al. Severe hepatic sinusoidal obstruction associated with oxaliplatinbased chemotherapy in patients with metstatic colorectal cancer. Ann Oncol 2004;15:460-466. doi: 10.1093/annonc/mdh095.

[66] Wolf PS, Park JO, Bao F, Allen PJ, DeMatteo RP, Fong Y. Preoperative chemotherapy and the risk of hepatotoxicity and morbidity after liver resection for metastatic colorectal cancer: a single institution experience. J Am Coll Surg 2013;216:41-49. doi: 10.1016/j.jamcollsurg.2012.08.030.

[67] Doroshow JH, Synold TW, Gandara D, Mani S, Remick SC, Mulkerin D, et al. Pharmacology of oxaliplatin in solid tumor patients with hepatic dysfunction: a preliminary report of the National Cancer Institute Organ Dysfunction Working Group. Semin Oncol 2003;30:14-19. doi: 10.1016/S00937754(03)00400-7.
[68] Teo YL, Ho HK, Chan A. Risk of tyrosine kinase inhibitors-induced hepatotoxicity in cancer patients: a meta-analysis. Cancer Treat Rev 2013; 39:199-206. doi: 10.1016/j.ctrv.2012.09.004.

[69] Hidalgo M, Siu LL, Nemunaitis J, Rizzo J, Hammond LA, Takimoto C, et al. Phase I and pharmacologic study of OSI-774, an epidermal growth factor receptor tyrosine kinase inhibitor, in patients with advanced solid malignancies. J Clin Oncol 2001;19:3267-3279.

[70] O'Bryant CL, Haluska P, Rosen L, Ramanathan RK, Venugopal B, Leong S, et al. An open-label study to describe pharmacokinetic parameters of erlotinib in patients with advanced solid tumors with adequate and moderately impaired hepatic function. Cancer Chemother Pharmacol 2012; 69:605-612. doi: 10.1007/s00280-011-1733-6.

[71] Zhang L, Ma S, Song X, Han B, Cheng Y, Huang C, et al. Gefitinib versus placebo as maintenance therapy in patients with locally advanced or metastatic non-small-cell lung cancer (INFORM; C-TONG 0804): a multicentre, double-blind randomised phase 3 trial. Lancet Oncol 2012;13:466475. doi: 10.1016/S1470-2045(12)70117-1.

[72] Ramanathan RK, Egorin MJ, Takimoto CH, Remick SC, Doroshow JH, LoRusso $\mathrm{PA}$, et al. Phase I and pharmacokinetic study of imatinib mesylate in patients with advanced malignancies and varying degrees of liver dysfunction: a study by the National Cancer Institute Organ Dysfunction Working Group. J Clin Oncol 2008;26:563-269. doi: 10.1200/JCO.2007.11.0304.

[73] O'Brien SG, Guilhot F, Larson RA, Gathmann I, Baccarani M, Cervantes F, et al. Imatinib compared with interferon and low-dose cytarabine for newly diagnosed chronic-phase chronic myeloid leukemia. N Engl J Med 2003;348: 994-1004. doi: 10.1056/NEJMoa022457.

[74] Shibata SI, Chung V, Synold TW, Longmate JA, Suttle AB, Ottesen LH, et al. Phase I study of pazopanib in patients with advanced solid tumors and hepatic dysfunction: a National Cancer Institute Organ Dysfunction Working Group study. Clin Cancer Res 2013;19:3631-3639. doi: 10.1158/10780432.CCR-12-3214.

[75] Miller AA, Murry DJ, Owzar K, Hollis DR, Kennedy EB, Abou-Alfa G, et al. Phase I and pharmacokinetic study of sorafenib in patients with hepatic or renal dysfunction: CALGB 60301. J Clin Oncol 2009;27:1800-1805. doi: $10.1200 / \mathrm{JCO} .2008 .20 .0931$

[76] Kirkwood JM, Bender C, Agarwala S, Tarhini A, Shipe-Spotloe J, Smelko B, et al. Mechanisms and management of toxicities associated with high-dose interferon alfa-2b therapy. J Clin Oncol 2002;20:3703-3718. doi: 10.1200/ JCO.2002.03.052.

[77] Fisher B, Keenan AM, Garra BS, Steinberg SM, White DE, DiBisceglie AM, et al. Interleukin-2 induces profound reversible cholestasis: a detailed analysis in treated cancer patients. J Clin Oncol 1989;7:1852-1862.

[78] Niu C, Yan H, Yu T, Sun HP, Liu JX, Li XS, Wu W, et al. Studies on treatment of acute promyelocytic leukemia with arsenic trioxide: remission induction, follow-up, and molecular monitoring in 11 newly diagnosed and 47 relapsed acute promyelocytic leukemia patients. Blood 1999;94:3315-3324.

[79] Haskell CM, Canellos GP, Leventhal BG, Carbone PP, Block JB, Serpick $A \mathrm{~A}$, et al. L-asparaginase: therapeutic and toxic effects in patients with neoplastic disease. N Engl J Med 1969;281:1028-1034. doi: 10.1056/ NEJM196911062811902.

[80] LoRusso PM, Venkatakrishnan K, Ramanathan RK, Sarantopoulos J, Mulkerin D, Shibata SI, et al. Pharmacokinetics and safety of bortezomib in patients with advanced malignancies and varying degrees of liver dysfunction: phase I NCI Organ Dysfunction Working Group Study NCI-6432. Clin Cancer Res 2012;18:2954-2963. doi: 10.1158/1078-0432.CCR-11-2873.

[81] Heddle R, Calvert AF. Hydroxyurea induced hepatitis. Med J Aust 1980;1: 121.

[82] McMaster KR 3rd, Hennigar GR. Drug-induced granulomatous hepatitis. Lab Invest $1981 ; 44: 61-73$. 